\title{
An Investigation into the Adaptability of Chinese Students in the UK from a Cross-Culture Perspective
}

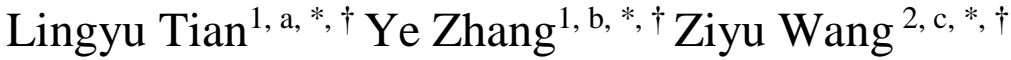

\author{
${ }^{1}$ The University of Manchester, England, UK \\ ${ }^{2}$ Central China Normal University, Wuhan, Hubei, China \\ ${ }^{*}$ Corresponding author email: ${ }^{a}$ lingyu.tian@postgrad.manchester.ac.uk, ${ }^{b}$ ye.zhang-11@postgrad.manchester.ac.uk \\ cziyuwang@mails.ccnu.edu.cn \\ These authors contributed equally.
}

\begin{abstract}
With the increase in the number of Chinese students studying in China, it has become increasingly important to study the adaptability of Chinese students in the new cultural environment. The main content of this research is to explore the influence of language mastery, academic activities, and social relations on the adaptability of Chinese students in the UK from a cross-cultural perspective. This article uses a combination of qualitative and quantitative methods to analyze the existing literature, and concludes that: Chinese students have difficulties in language expression skills during their study abroad, but the new language environment still greatly improves the language of Chinese students. The process of Chinese students adapting to the British education system in cross-cultural adjustment is active and complicated, but however, there are individual differences in whether there are better academic performances, a good and stable teacherstudent relationship is important for students to adapt to the new cultural environment positive influence, but to better integrate into the new cultural environment, students also need to overcome the obstacles of a strong co-national relationship. This article fills the gaps in the literature review on the adaptability of Chinese students in the UK from a cultural perspective. It combines predecessors' research on Chinese students' language mastery, academic performance, and adaptability of social relations from a cultural perspective, and summarizes the research on adaptability from a cultural perspective, laying an important foundation on future research in this field.
\end{abstract}

Keywords: Language Mastery, Academic Achievement, Social Relations, Adaptability, Chinese International Students.

\section{INTRODUCTION}

In recent years, the internationalization of higher education has become more and more common, and a large number of students are studying in the UK, which has aroused widespread concerns and research of educators $[1,2]$. Studying abroad can promote students to acquire knowledge but also acquire cross-cultural ability, which enables students to express themselves effectively in different cultural backgrounds [1]. However, Chinese students are also faced with a series of challenges and difficulties due to cultural differences, especially in language learning and social relations, which will affect their academic achievements [3]. Gu also believe that the process of foreign students' adaptation is a complex one, which is influenced by language mastery, social interaction, personal development, and academic achievements [4]. When students are driven out of their comfort zone and take on new responsibilities, they are often required to develop new study habits to adapt to the new curriculum, rearrange work priorities, make new friends and seek help [4]. However, in the previous literature, authors have usually studied only one aspect of the adaptation of Chinese students in the UK, and few authors have summarized the data in this field. This paper aims to fill in this gap. Based on previous studies and their data, it is concluded that they mainly focus on the impact of intercultural competence on the adaptability of Chinese students in the UK from three aspects: language mastery, academic performance and social relations. It is found in this paper that even though Chinese students encounter many challenges in language communication, their language skills are still promoted in the new language environment. The intercultural adaptation of Chinese students in the British education system is an active and 
complex process; A good and stable teacher-student relationship plays a positive role in students' adaptation to the new cultural environment, but students need to overcome the obstacles of a strong co-national relationship. Next, this paper will introduce the adaptation of Chinese students in the UK from three aspects — English language proficiency, academic engagement and social relationship.

\section{ENGLISH LANGUAGE PROFICIENCY}

Among the many challenges students face, language proficiency is the most prominent one because the degree of language mastery is closely related to academic achievement, curriculum discussion in and out of class, daily communication in life, etc. [3]. It seems that students with higher English levels will encounter more opportunities, which can help them adapt to the environment more smoothly. On the contrary, students with lower English proficiency seem to have more difficulties [3]. However, Chinese students' English teaching focused on exam papers instead of speaking tests for recent decades. With a certain number of words and a certain number of grammar as the ultimate goal, most teachers are more concerned about completing the school's teaching plan rather than improving students' communicative competence [5]. The exam pays great attention to the main points of language but neglects communicative competence. In this case, the motivation of both teachers and students is included in the question of how to pass the examination. As a result, English education stays in books, ignoring the cultivation of students' ability to use language [5].

As far as Chinese students' English learning is concerned, from the perspective of skills acquisition theory, the acquisition of second language skills can be divided into three stages: declarative knowledge, procedural knowledge, and automatic knowledge. Declarative knowledge emphasizes grammar and rules, while procedural knowledge pays attention to feedback, both of which do not need much practice. They are more suitable for classroom completion, but automatic knowledge needs to use the target language smoothly and error-free in extensive practice [6]. Chinese teaching mode only attaches importance to declarative and procedural training but does not create an automatic language environment. This makes Chinese students still in an obstacle position in communication, even though they have a large vocabulary, solid grammar rules, and systematic knowledge. Studying abroad is more conducive to promoting automation [7]. Students can have more opportunities to develop relationships with people whose mother tongue is the target language, and there are many inputs, outputs, and interactions. First of all, Chinese students play different social roles in numerous interpersonal relationships by participating in different language practices and get a lot of communication opportunities, thus improving their fluency [6]. In addition, Chinese students use a lot of English reading and writing to deal with vocabulary indepth and discuss topics in deeper interpersonal relationships, thus improving their vocabulary [8]. Most importantly, Chinese students have the opportunity to observe how people convey proper politeness and etiquette in their speech acts during their study abroad or actual dialogues. Learners can practice reasoning and understanding through interaction with interlocutors and interaction between interactive backgrounds and gain pragmatic awareness and practice [9].

As China's current examination system and teaching mode do not pay attention to students' use of English, students are used to focusing most of their energy on the accumulation of vocabulary and grammar knowledge. Meanwhile, Chinese students' lack of oral expression and pragmatic ability can be compensated by cross-cultural learning. For example, Hymes, an American social linguist, pointed out in his book Communicative Competence: "Language must have a usage theory. Otherwise, grammar rules will be meaningless [2]." His "Usage Theory" refers to the appropriateness of using language in communication. At the same time, Zhang and Wang also insisted that if we want to master a language, we must have a sufficient understanding of the rich social and cultural background of the language, and rich social and cultural knowledge is also beneficial to the understanding and use of the language, which complements each other [5]. Therefore, even though Chinese students have great challenges in language expression during their study abroad, the second language environment has greatly promoted Chinese students' language improvement.

\section{ACADEMIC ENGAGEMENTS}

The inadequate academic engagement of Chinese students is reflected in many phenomena. First of all, some Chinese students did not participate in group discussions at the early stage of their study in Britain. Due to the influence of Confucianism, Chinese students are not accustomed to actively answering, interrupting, commenting, or criticizing [10]. They prefer structured learning with precise and detailed guidance and goals rather than open discussion [11]. This leads some Chinese students to remain silent in group discussions, considered a risk-avoidance strategy [12]. They are afraid that others will deny the views expressed in the discussion. In Chinese traditional morality, humility is emphasized, and few students are willing to express their different opinions in public, which may be considered a manifestation of propaganda. At the same time, they think that criticizing others will affect their interpersonal communication because of cultural factors. Because in traditional Chinese Confucianism, listening to each other is out of politeness, and it is impolite to interrupt others 
when they speak. These fears push them to use silence to avoid what they think may happen. Second, Chinese students prefer the assessment based on personal assignments, reflecting their strength and efforts, and have a negative tendency to do group assignments, especially when such assignments are marked by groups [13]. This phenomenon is mainly related to China's highly competitive education system, even though Chinese students recognize the positive benefits of group work. However, due to their long-term dependence on individualism and competitive spirit, it is often difficult for them to immediately adapt to the educational values advocated by western educators, such as cooperative learning and achievement sharing [12].

However, a large number of studies have shown that the learning methods of Confucian traditional culture can change with time, and Chinese students will adjust to the new learning and cultural background [14]. Although students come from a teacher-centered learning environment, they quickly adapt to the student-centered learning method [2]. In 2012, twenty-four in-depth interviews were conducted with 16 students (8 Chinese students and 8 British students), and it was found that Chinese students promote cultural adaptation through group cooperation. They realize that contradictory views do not necessarily mean rudeness or unfriendly and that expressing different opinions openly results from critical thinking and the normal discussion process [2]. Meanwhile, in the process of group discussion, the evaluation of group members promotes students' selfreflection. Through teamwork, Chinese students learn to understand team members from a cultural perspective instead of complaining about different attitudes and behaviors [2]. This process is an upgrade phase for them. After breaking through the cultural barriers, they will have a better awareness of cultural integration, which can help them better understand the curriculum content and improve their grades.

Some people think that Chinese students' crosscultural adaptation cannot be changed in a short time, which is not only related to the length of Chinese students' stay in the UK but also related to confidence, emotion, and other factors. After all, the main purpose of international students is to concentrate on their studies, and most students seldom consider changing the nature of their original culture for the new environment. Turner interviewed nine Chinese graduate students in British schools every month from 2001 to 2002 to discuss the development of Chinese students' learning orientation during their study in the UK [15]. The results showed that due to the cultural implications of British academic conferences, the participants' basic learning methods had not changed significantly in the past year, and they experienced a high degree of emotional isolation and loneliness, which affected their academic confidence. Some essential customs are hard for them to change, but the new environment easily influences potential things like emotions. In addition, foreign students' own cultural heritage may positively or negatively impact their studies. Having a clear sense of self-awareness may help them find a solution to this problem.

Therefore, the early academic achievements of Chinese students in the UK are challenged by poor education. Whether students can adapt to the British education system in this cross-cultural adaptation and have better academic achievements is the interaction between a series of active and complex processes, with great individual differences.

\section{SOCIAL RELATIONSHIPS}

There is a problem with establishing good social relationships, which has varying degrees of impact on students adapting to the new cultural environment [16]. However, in recent years, many scholars' research on Chinese students studying abroad has mostly focused on their academic life, paying particular attention to their level of classroom participation, learning style, and recently they have been with their peers $[16,17]$. The level of academic achievement compared to people, and few studies have studied the social and cultural interactions between Chinese students and people from different backgrounds $[18,19]$. Taylor and Ali argue that the earlier students start to develop new social relationships, the smoother they will adjust to the new cultural environment [3]. Therefore, Chinese students in the UK should be encouraged to learn more about cultural and regional differences to help them effectively integrate and participate in the new social environment. This paper mainly discusses two aspects of the social relationship that Chinese students face in adapting to the new cultural environment: the social relationship between Chinese international students and teachers; and the social relationship between Chinese international students.

On the one hand, the establishment of the relationship between Chinese international students and teachers greatly affects the adaptability of international students to the new culture, and this relationship is complicated. Teachers play a pivotal role in cultivating students' knowledge and skills and serve as potential role models and mentors [20]. Denzine and Pulos believe that the accessibility of teachers is an important prerequisite that must be guaranteed to promote positive teacher-student interaction [21]. Hagenauer and Volet further explained this [22]. They believed that approachable lecturers and tutors who answered students' questions on time and communicated expectations about homework were described as very helpful for students in learning and adapting to the university, success. In addition, experiments have shown that when the frequency of communication between teachers and students rarely occurs, it may be difficult to establish a positive relationship [22]. Therefore, more frequent out-of-class 
interactions between students and their university teachers (e.g., office visits) will improve the relationship between them and bring students closer to the university [22].

However, not all student groups have a strong teacher-student relationship, and there are many reasons for this phenomenon. Firstly, Cotten and Wilson show that extracurricular interactions between students and lecturers are often infrequent in the new cultural environment. The interactive content is mainly focused on academic tasks, and rarely goes beyond curriculumrelated problems [23]. Secondly, compared to middle schools, the teaching environment of universities is often more scattered, the frequency of interaction between teachers and students is lower, and the relationship is more fragile [22]. In other words, the more infrequent frequency of contact in higher education makes it more difficult to establish social relationships between faculty and students. Also, some stereotypes can affect the relationship between teachers and students [20]. For example, racial stereotypes can affect teachers' perceptions and interactions with students [24]. For Chinese international students, there are two common stereotypes. The first stereotype is that Asians are good at mathematics. Chinese students are considered "gifted" in mathematics; the second stereotype is that they are considered silent in their studies and passive in interpersonal communication. It even affects the normal communication between teachers and students [20]. As Steele and Aronson explain, negative stereotypes can generate self-induced threats to members of stereotype groups and inhibit their performance in the tasks that are the targets of that particular stereotype [25]. In other words, negative stereotypes will inhibit students' positive performance.

On the other hand, making new friends and eventually establishing a new social support system is also regarded as an important part of the adjustment process of international students, and making new friends in the UK helps to learn more about the local culture and improve adaptability [3]. Whitworth proposes that learners need to go beyond their comfort zone to develop friendships and actively participate in social activities to interact with others [26]. The school's study group, partner support, and teacher support prevent Chinese students from staying in the comfort zone of interpersonal relationships. They have to step out of the Chinese-only group and establish contacts with students in the UK and other countries. In addition, the randomness of partner support and the distribution of study groups will also cause some cultural collisions between Chinese students and foreign students [2]. However, Kinginger found that Chinese international students are more sensitive to the new environment [27]. As a result, the level of participation is not as high as expected, and most Chinese international students return to the social relations of native speakers after completing their studies. In addition, the social reach of Chinese students is not recognized by foreign students. This phenomenon is reflected in an interview by Spencer-Oatey [16]. In the opinion of some foreign interviewees, Chinese international students think it is not necessary to have social contact with foreigners because these Chinese students have their fixed social groups and can use their familiar websites to make friends [16]. In addition, Cao also insists that for most Chinese international students, making new foreign friends and establishing social relationships to adapt to the new cultural environment is largely unworkable [28]. Therefore, the strong co-national relationship affects the development of Chinese students' social relations in the new environment and hinders their long-term adaptation [28-30].

In short, good and stable social relations positively affect students adapting to the new cultural environment [28]. A good social relationship between students and teachers is premised on the accessibility of teachers and frequent interaction with students. The dispersion of the teaching environment and the teacher's stereotypes of students will harm the cultural exchanges between teachers and students. In addition, to better integrate into the new cultural environment, students also need to overcome the barriers of the strong co-national relationship and actively establish new social relationships.

\section{CONCLUSION}

This paper mainly studies the influence of language mastery, academic achievements, and social relations on the adaptability of Chinese students studying in Britain. Studying abroad can help Chinese students acquire new knowledge and help them acquire cross-cultural ability, thus helping them adapt to different cultures and express themselves better. However, due to cultural differences, Chinese international students face some new difficulties and challenges in adapting to the new environment, especially in the three aspects of language mastery, academic performance, and social relations. These challenges are mainly manifested in students' low English level and their inability to adapt quickly to the learning and living environment. Due to cultural differences and different educational systems, the methods of curriculum sets are not suitable. The establishment of relationships with classmates and teachers affects their ability to adapt in the UK. After sorting out the previous literature, the main findings of this paper are as follows: Although Chinese students are facing great challenges in language skills while studying abroad, the second language environment has greatly promoted the improvement of Chinese students' language level; Whether students can adapt to the British education system in cross-cultural adaptation is an active and complex process. Still, there are individual differences in whether students have better academic achievements. A 
good and stable teacher-student relationship will help students adapt to the new cultural environment. However, to better integrate into the new cultural environment, students still need to overcome the obstacles of strong ethnic relations. Language mastery, academic achievements, and social relations are important parts to measure the degree of international students adapting to the new cultural environment. This paper holds that the new cultural environment promotes the mastery of language; The adaptability to the new environment is also reflected in academic achievements. Whether establishing good social relationships will affect the foreign students' adaptations to the new environment. In the future study of Chinese students' adaptability in Britain, researchers can study the influence of language mastery, academic achievements, and social relations and provide more comprehensive research with a wider range. For example, overseas life experience will also have an impact on the adaptability of Chinese students. Furthermore, more comprehensive studies will also research the adaptability of Chinese international students in the UK more adequately and completely.

\section{REFERENCES}

[1] Summers, M., \& Volet, S. (2008). Students' attitudes towards culturally mixed groups on international campuses: impact of participation in diverse and non-diverse groups. Studies in higher education, 33(4), 357-370.

[2] Wang, Y., Harding, R., \& Mai, L. W. (2012). Impact of cultural exposure on young Chinese students' adaptation in a UK business school. Studies in Higher Education, 37(5), 621-639. https://doi.org/10.1080/03075079.2010.536528

[3] Taylor, G., \& Ali, N. (2017). Learning and living overseas: Exploring factors that influence meaningful learning and assimilation: How international students adjust to studying in the UK from a socio-cultural perspective. Education Sciences, $7(1)$. https://doi.org/10.3390/educsci7010035

[4] Gu, Q., M. Schweisfurth, and C. Day. 2010. Learning and growing in a 'foreign' context: Intercultural experiences of international students. Compare 40: 7-23.

[5] Zhang, H., \& Wang, N. (2016). Sociolinguistics and English teaching in China. Theory and Practice in Language Studies, 6(4), 830-834.

[6] DeKeyser, R., \& Criado, R. (2012). Automatization, skill acquisition, and practice in second language acquisition. The encyclopedia of applied linguistics.

[7] Li, B. (2009). Processed-Centered Teaching and Its Implications in English Teaching in China. English
Language Teaching, 2(1), 24-30. https://doi.org/10.5539/elt.v2n1p24

[8] Lybeck, K. (2002). Cultural identification and second language pronunciation of Americans in Norway. The Modern Language Journal, 86(2), 174191.

[9] Taguchi, N. (2011). The effect of L2 proficiency and study-abroad experience on pragmatic comprehension. Language Learning, 61(3), 904-939.

[10] Holmes, P. (2004). Negotiating differences in learning and intercultural communication: Ethnic Chinese students in a New Zealand university. Business Communication Quarterly, 67(3), 294-307.

[11] Phuong-Mai, N., C. Terlouw, and A. Pilot. 2006. Culturally appropriate pedagogy: The case of group learning in a Confucian Heritage Culture context. Intercultural Education 17, no. 1:119.

[12] Zhang, Z., and J. Xu. 2007. Understanding Chinese international graduate students'adaptation to learning in North America: A cultural perspective. Higher Education Perspectives 3, no. 1: 4559.

[13] Volet, S., and G. Ang. 1998. Culturally mixed groups on international campuses: An opportunity for inter-cultural learning. Higher Education Research \& Development 17, no. 1: 523.

[14] Volet, S. E., \& Renshaw, P. D. (1996). Chinese students at an Australian university: Adaptability and continuity. Hong Kong University Press.

[15] Meyer, D. K., \& Turner, J. C. (2006). Reconceptualizing emotion and motivation to learn in classroom contexts. Educational Psychology Review, 18(4), 377-390.

[16] Spencer-Oatey, H., \& Xiong, Z. (2006). Chinese student's psychological and sociocultural adjustments to Britain: An empirical study. Language, Culture and Curriculum, 19(1), 37-53.

[17] Hodkinson, C. S., \& Proropat, A. E. (2014). Chinese students' participation: the effect of cultural factors. Education + Training, 56(5), 430-446.

[18] Jin, L., \& Cortazzi, M. (2006). Changing practices in Chinese cultures of learning. Language, Culture and Curriculum, 19(1), 5-20.

[19] Crawford, I., \& Wang, Z. (2015). The effect of work placements on the academic performance of Chinese students in UK higher education. Teaching in Higher Education, 20(6), 569-586. https://doi.org/10.1080/13562517.2015.1045860

[20] Cherng, H. Y. S. (2017). The ties that bind: Teacher relationships, academic expectations, and 
racial/ethnic and generational inequality. American Journal of Education, 124(1), 67-100. https://doi.org/10.1086/693955

[21] Denzine, G. M., \& Pulos, S. (2000). College students' perceptions of faculty approachability. Educational Research Quarterly, 24, 56-66.

[22] Hagenauer, G., \& Volet, S. E. (2014). Teacherstudent relationship at university: an important yet under-researched field. Oxford Review of Education, 40(3), 370-388. https://doi.org/10.1080/03054985.2014.921613

[23] Cotten, S. R., \& Wilson, B. (2006). Student-faculty interactions: Dynamics and determinants. Higher Education, 51(4), 487-519. https://doi.org/10.1007/s10734-004-1705-4

[24] Yeh, C. J., Kim, A. B., Pituc, S. T., \& Atkins, M. (2008). Poverty, loss, and resilience: The story of Chinese immigrant youth. Journal of Counseling Psychology, 55(1), 34.

[25] Steele, C. M., and J. A. Aronson. (1995). "Stereotype Threat and the Intellectual Test Performance of African Americans." Journal of Personality and Social Psychology 69: 797-811. doi:10.1037/0022-3514.69.5.797

[26]Withworth, J. (2006). Writing poetry second edition. London: A \& C Black.

[27] Kinginger, C. (2011). Enhancing language learning in study abroad. Annual review of applied linguistics, 31(1), 58-73.

[28] Cao, C., Zhu, C., \& Meng, Q. (2017). Predicting Chinese international students' acculturation strategies from socio-demographic variables and social ties. Asian Journal of Social Psychology, 20(2), 85-96. https://doi.org/10.1111/ajsp.12171

[29] Lehto, X. Y., Cai, L. A., Fu, X., \& Chen, Y. (2014). Intercultural interactions outside the classroom: Narratives on a US campus. Journal of College Student Development, 55(8), 837-853. https://doi. org/10.1353/csd.2014.0083

[30] Hendrickson, B., Rosen, D., \& Aune, R. K. (2011). An analysis of friendship networks, social connectedness, homesickness, and satisfaction levels of international students. International Journal of Intercultural Relations, 35(3), 281-295. https://doi.org/10.1016/j.ijintrel.2010.08.001 